\title{
Insulin resistance, growth factors and cytokine levels in overweight women with breast cancer before and after chemotherapy
}

\author{
Eftychia Chala, ${ }^{1}$ Christos Manes, ${ }^{2}$ Helias Iliades, ${ }^{3}$ Georgios Skaragkas, ${ }^{2}$ \\ Despina Mouratidou, ${ }^{3}$ Efthymios Kapantais ${ }^{1}$
}

${ }^{1}$ Department of Diabetes-Obesity-Metabolism, Metropolitan Hospital, Neo Faliro, Greece, ${ }^{2}$ Diabetes Center, Papageorgiou Hospital, ${ }^{3} 3^{\text {rd }}$ Department of Clinical Oncology, Theagenio Hospital, Thessaloniki, Greece

\begin{abstract}
OBJECTIVE: To evaluate insulin values, insulin resistance, growth factors and cytokine levels in women suffering from breast cancer and the effect of chemotherapy on these parameters. DESIGN: In a prospective study, glucose and insulin values were determined in ten previously undiagnosed diabetic postmenopausal women with stage IV breast cancer (hepatic metastases excluded) during an oral glucose tolerance test (OGTT) carried out after a glucose load of 75g. At baseline, leptin, Interleukin-1 (IL-1), Interleukin-6 (IL-6), Interleukin-8 (IL-8), InsulinGrowth Factor-1 (IGF-1), Tumor-Necrosis-Factor- $\alpha$ (TNF- $\alpha$ ), Vascular Endothelial Growth Factor (VEGF) and Platelet Derived Growth Factor (PDGF) levels were also determined using appropriate methodolody. Insulin resistance and $\beta$-cell function were calculated (HOMA-model). All women were evaluated prior to and after chemotherapy applied for 6 months. RESULTS: 1) Insulin levels at 120 minutes of the OGTT were higher before compared to postchemotherapy (Mean \pm SD: $170.39 \pm 78.07$ vs $111.75 \pm 76.19, p=0.037) .2)$ Body mass index $(B M I)$ was an important predictor of post-glucose load insulin levels both before (coefficient $=1.051$, $p=0.004)$ and after chemotherapy (coefficient $=0.711, p=0.003) .3$ ) Before chemotherapy BMI values were positively related to PDGF levels $\left(r_{s}=0.685, p=0.029\right)$, while after chemotherapy this relationship became non-significant $\left(r_{s}=0.188, p=0.603\right)$. Before chemotherapy there was a negative relationship between VEGF and waist circumference (coefficient $=-\mathbf{0 . 5 4 2}, p=0.023$ ). CONCLUSIONS: Post-glucose load insulin values significantly decrease after chemotherapy. There is a positive relationship between BMI and post-glucose load insulin before and after chemotherapy. The contribution of the reduction in insulin, a known growth factor, to the outcome of chemotherapy in these patients remains speculative at present.
\end{abstract}

Key words: Body mass index, Breast cancer, Chemotherapy, Cytokines, Insulin, Obesity, PDGF, VEGF 


\section{INTRODUCTION}

The twenty-first century has been characterized among other things, as the century of the obesity epidemic. ${ }^{1}$ Obesity, defined as excess body fat, is a complex disorder that involves both genetic and environmental influences leading to high energy intake and low physical activity coupled with a metabolic derangement. ${ }^{1}$ Apart from the obvious aesthetic drawback, obesity leads to many health burdens, such as metabolic (hyperinsulinemia, dyslipidemia, type 2 diabetes, hyperuricemia, gallstone disease), orthopedic (osteoarthritis, mainly knee and hip), pulmonary (sleep-apnea syndrome, Pickwick syndrome), cardiovascular (hypertension, coronary heart disease, congestive heart failure, stroke, peripheral atherosclerotic disease, phlebitis) and surgical problems (gallstone disease, hernia). ${ }^{1}$

Moreover, obese persons are more often afflicted by various types of cancers, including colorectal, gallbladder, pancreatic, liver and renal and, more importantly, hormone-dependent cancers such as endometrial, ovarian, prostate and especially breast cancer. $^{1,2}$

Regarding breast cancer in particular, its etiology is multifactorial, involving both genetic and environmental factors. Mutations in the BRCA1 and $\mathrm{BRCA}^{3,4}$ genes have been associated with an increase in the lifetime risk for breast cancer, but these highly penetrant mutant alleles are not only relatively rare in the general population but also hard to interfere with, and therefore are of less importance in health policy. On the other hand, the relationship between breast cancer and obesity, although less clear, is more important for the general population, especially postmenopausally. ${ }^{5-8}$ Although age has a significant impact on the risk of breast cancer, post-menopausal obese women are at higher risk than post-menopausal lean women, pointing to an effect of adiposity on breast cancer risk. Fat distribution also affects the risk of breast cancer: an increased risk is more highly correlated with central obesity than with BMI. When compared with controls, breast cancer patients have a significantly lower subcutaneous to central fat ratio, as can be determined by CT scanning. Other risk factors for breast cancer development are early menarche, late first full-term pregnancy and late menopause, conditions associated with a cumulative exposure of mammary tissue to estrogens. ${ }^{9}$

Moreover, certain growth factors, such as PDGF $^{10}$ and VEGF, ${ }^{11-14}$ as well as insulin and cytokines, especially TNF- $\alpha$, IL-8, IL-6, ${ }^{12,13}$ seem to play important but only partially defined roles in mammary tumor development and progression. PDGFs ${ }^{15}$ are important for normal tissue growth and maintenance. Overexpression of the classical PDGFs, PDGF-A and PDGF-B has been linked to several diseases, including fibrotic disease, arteriosclerosis and cancer. ${ }^{16}$ VEGF-A is known to play an important role in tumor angiogenesis. Three additional members of the VEGF family, VEGF-B, C and D, have been discovered. VEGF-C and D are ligands for VEGF receptor-3 which is expressed in the endothelium of lymphatic vessels. Thus, it has been suggested that VEGF-C and D may play a role in the development of lymphatic vessels in solid tumors. ${ }^{11}$ On the other hand, normal human mammary epithelial cells constitutively produce IL-6, IL-8 and a non-secreted form of TNF. ${ }^{17}$ IL- 6 and TNF- $\alpha$ have an important role in regulating estrogen synthesis in peripheral tissues, including normal and malignant breast tissue, probably by increasing the activities of aromatase, 17ß-hydroxysteroid dehydrogenase and estrone sulfatase..$^{18}$ Moreover, cytokines, as a marker of low-grade inflammation, are implicated in insulin-resistant states and hyperinsulinemia. It has been proposed that insulin and insulin-like growth factor- 1 act as autocrine and paracrine growth factors in human breast cancer cells, possibly exerting a mitogenic effect on mammary tissue. ${ }^{19,20}$ Moreover, it is suggested that insulin interacts with estrogen receptors in mammary tissue, augmenting estrogen effect on breast cancer development. ${ }^{21,22}$ In breast cancer cells exposed to insulin in vitro, the number of insulin receptors dropped, which is an expected normal response. However, when the cells were bathed in a solution containing estrogens and insulin, the number of estrogen receptors increased significantly (12 times), a strong indication for increased tumor growth and proliferation potential. Finally, it has been shown that insulin inhibits the production of sex-hormone binding globulin (SHBG), leading to higher free estrogen levels. ${ }^{23,24}$ 
In accordance with this knowledge, postmenopausal women with breast cancer have lately been shown to have higher PDGF, VEGF and insulin levels than controls and, even more significantly, it has been proposed that among breast cancer patients, those with the higher levels of the above parameters have the most ominous prognosis even after correction for BMI and adjustment for age, grade and estrogen status. ${ }^{10,11,13,14,25}$

The aim of the present study was to evaluate insulin concentration, insulin-resistance as well as insulin growth factor and cytokine levels in women suffering from breast cancer, their relationship with anthropometric measurements (BMI and waist circumference) and the effect of chemotherapy on these parameters.

\section{PATIENTS AND METHODS}

The study group included 10 postmenopausal women, not previously diagnosed as diabetic, with stage IV breast cancer but without hepatic metastases. All women were recruited in the Theagenio Hospital, Department of Clinical Oncology, Thessaloniki, Greece, and informed consent was obtained from each subject. The clinical characteristics of the women examined were $($ Mean $\pm \mathrm{SD})$ : age $=63.2 \pm 8.5$ years (range 49-74), BMI $=27.64 \pm 1.93 \mathrm{~kg} / \mathrm{m}^{2}(25.11$ 30.42 ) and waist circumference (WC) $=100.8 \pm 7.6$ $\mathrm{cm}$ (90-113). All women were subjected to an OGTT and glucose and insulin values were determined before and 2 hours after glucose (75gr) were orally administered. Baseline values of leptin, IL-1, IL-6, IL-8, IGF-1, TNF- $\alpha$, VEGF, PDGF and IGF-1 levels were also determined. IGF-1 was determined by radioimmunoassay kit. Elisa was employed to determine cytokines: Il-1 and Il- 6 were measured by the chemiluminescent Elisa kit (assay range 0.5-5 $\mathrm{pg} / \mathrm{ml}$ and sensitivity $0.5 \mathrm{pg} / \mathrm{ml}$ ), Il-8 was measured by the colorimetric Elisa kit (assay range 25.6-1000 $\mathrm{pg} / \mathrm{ml}$ and sensitivity $<2 \mathrm{pg} / \mathrm{ml}$ ), TNF-a was measured by the chemiluminescent Elisa kit (assay range $2-20000 \mathrm{pg} / \mathrm{ml}$ and sensitivity $1 \mathrm{pg} / \mathrm{ml}$ ) and VEGF was measured by the colorimetric Elisa kit (assay range $15.6-1000 \mathrm{pg} / \mathrm{ml}$ and sensitivity $<5 \mathrm{pg} / \mathrm{ml}$ ). For PDGF we used sandwich Elisa, for leptin the Leptin Human Elisa kit (assay range 0.5-100 ng/ml and sensitivity $0.5 \mathrm{ng} / \mathrm{ml}$ ) and for insulin we used the Human Insulin Elisa kit (assay range 2-200 $\mu \mathrm{U} / \mathrm{ml}$ and sensitivity $2 \mu \mathrm{U} / \mathrm{ml}$ ). (IL-1, IL-6, IL-8, TNF- $\alpha$, VEGF, PDGF: "Endogen Search-light" Bonn-Germany; Insulin, Leptin: "Linco Research", Missouri, USA.) Insulin-resistance and $\beta$-cell function were calculated using the $\mathrm{HOMA}^{26}$ method \{insulin $\mathrm{x}$ glucose/22.5 for insulin resistance and $20 \mathrm{x}$ insulin/(glucose-3.5) for $\beta$-cell function, respectively\}. The area under insulin and glucose during the OGTT were also calculated. All women were subjected to six cycles of chemotherapy which consisted of intravenous injections of fluorouracil (500mg per square meter of body surface area), epirubicin (90mg per square meter) and cyclophosphamide (500mg per square meter) every four weeks. At the end of the six-month period they were subjected to the same measurements. Chemotherapy was considered successful when the disease remained stable, which was the case in all of our patients. Basic variables and serum parameters were expressed as mean \pm standard deviation. Statistics included paired t-test whenever applicable, Wilcoxon matched paired sign rank test, parametric and non-parametric correlation ( $\mathrm{r}$ Pearson: $r$ and $r$ Spearman: $r_{s}$, respectively), and multiple regression analysis. Calculations were carried out using SPSS statistical package version 11.5. Results were considered significant when $\mathrm{p}<0.05$.

\section{RESULTS}

Tables 1A, 1B and $1 \mathrm{C}$ show descriptives for all parameters measured and calculated (insulin resistance, $\beta$-cell function and area under insulin and glucose curve) before and after chemotherapy. It should be emphasized that no difference was noticed in anthropometric parameters, and notably in BMI, before or after chemotherapy.

Of all the parameters studied, only insulin levels at 120 minutes after glucose administration showed statistically significant differences between values obtained before and after chemotherapy (170.39 \pm 78.07 vs. $111.75 \pm 76.19 \mu \mathrm{U} / \mathrm{ml}, \mathrm{p}=0.037$ ) (Table $1 \mathrm{~A}$, Figure 1A). Fasting and postprandial glucose levels did not significantly differ before and after chemotherapy, though postprandial values were lower after treatment $(p=0.139)$ (Table 1A, Figure 1B). 
Table 1A. Comparison of parameters measured at time 0 and 120 minutes of the OGTT before and after 6 months of chemotherapy.

\begin{tabular}{lccc}
\hline & $\begin{array}{c}\text { Before chemotherapy } \\
(\text { mean } \pm S D)\end{array}$ & $\begin{array}{c}\text { After 6 mos of chemotherapy } \\
(\text { mean } \pm S D)\end{array}$ & $\begin{array}{c}\text { Difference between means } \\
\text { p-value }\end{array}$ \\
\hline Glucose $0(\mathrm{mg} / \mathrm{dl})$ & $112.50 \pm 27.93$ & $120.70 \pm 50.49$ & 0.308 \\
Glucose $120(\mathrm{mg} / \mathrm{dl})$ & $202.00 \pm 112.21$ & $173.00 \pm 96.55$ & 0.139 \\
Insulin $0(\mu \mathrm{U} / \mathrm{ml})$ & $28.14 \pm 9.00$ & $31.93 \pm 21.02$ & 0.878 \\
Insulin $120(\mu \mathrm{U} / \mathrm{ml})$ & $170.39 \pm 78.07$ & $111.75 \pm 76.20$ & 0.037 \\
BMI $\left(\mathrm{kg} / \mathrm{m}^{2}\right)$ & $27.64 \pm 1.93$ & $27.59 \pm 1.88$ & 0.889 \\
\hline
\end{tabular}

For SI units multiply by 0.05 for glucose and 7.175 for insulin.

Table 1B. Comparison of parameters measured at base line before and after 6 months of chemotherapy

\begin{tabular}{lccc}
\hline & $\begin{array}{c}\text { Before } \\
(\mathrm{mean} \pm \mathrm{SD})\end{array}$ & $\begin{array}{c}\text { After } \mathbf{6} \text { mos of chemotherapy } \\
(\text { mean } \pm \text { SD })\end{array}$ & $\begin{array}{c}\text { Difference between means } \\
\text { p-value }\end{array}$ \\
\hline IGF-1 $(\mu \mathrm{g} / \mathrm{l})$ & $46.60 \pm 18.84$ & $52.49 \pm 42.59$ & 0.767 \\
IL-1 $(\mathrm{pg} / \mathrm{ml})$ & $1.11 \pm 0.60$ & $1.63 \pm 2.23$ & 0.683 \\
IL-6 $(\mathrm{pg} / \mathrm{ml})$ & $4.44 \pm 7.23$ & $2.70 \pm 2.34$ & 0.779 \\
IL-8 $(\mathrm{pg} / \mathrm{ml})$ & $36.34 \pm 41.09$ & $26.17 \pm 46.15$ & 0.721 \\
Leptin $(\mathrm{ng} / \mathrm{ml})$ & $27.50 \pm 20.08$ & $25.53 \pm 26.19$ & 0.767 \\
PDGF $(\mathrm{pg} / \mathrm{ml})$ & $79336.00 \pm 36394.65$ & $66410.00 \pm 34430.27$ & 0.285 \\
VEGF $(\mathrm{pg} / \mathrm{ml})$ & $94.82 \pm 90.65$ & $265.40 \pm 309.53$ & 0.074 \\
TNF- $\alpha(\mathrm{pg} / \mathrm{ml})$ & $192.44 \pm 405.84$ & $6.27 \pm 8.55$ & 0.674
\end{tabular}

Table 1C. Comparison of parameters calculated before and after 6 months of chemotherapy.

\begin{tabular}{lccc}
\hline & $\begin{array}{c}\text { Before chemotherapy } \\
(\text { mean } \pm \text { SD })\end{array}$ & $\begin{array}{c}\text { After 6 mos of chemotherapy } \\
(\text { mean } \pm \text { SD })\end{array}$ & p-value \\
\hline Insulin-resistance HOMA & $7.87 \pm 3.20$ & $10.64 \pm 9.63$ & 0.386 \\
$\beta$-cell function HOMA & $261.86 \pm 164.07$ & $321.59 \pm 324.81$ & 0.646 \\
Area under glucose curve & $18870.00 \pm 8199.96$ & $17622.00 \pm 8452.50$ & 0.260 \\
Area under insulin curve & $11912.04 \pm 4780.69$ & $8621.04 \pm 4978.79$ & 0.074 \\
\hline
\end{tabular}

Bivariate Correlation analysis of insulin levels at 120 minutes of the OGTT and the other factors before and after chemotherapy reveals that before therapy, insulin levels are not related to cytokines and anthropometric factors, while after chemotherapy, insulin levels at 120 minutes of the OGTT are correlated only to BMI $(r=0.709, p=0.022)$. Further exploration of the factors determining insulin levels 120 minutes after glucose administration, with multiple regression analysis, reveals that before therapy, $86.4 \%$ of the variability of the insulin levels is attributed $(\mathrm{F}=7.96, \mathrm{p}=0.021)$ to $\mathrm{BMI}$ (coefficient $=1.051, \mathrm{p}=0.004)$ and to PDGF (coefficient $=$ $-0.955, p=0.006$ ) (Table 2A). After chemotherapy,
IL-6 and BMI are the main predictors of 120 minutes insulin levels. Specifically, $81.4 \%$ of the variability of insulin levels post chemotherapy is attributed $(\mathrm{F}=15.31, \mathrm{p}=0.003)$ to BMI (coefficient $=$ $0.711, \mathrm{p}=0.003$ ) and to IL-6 (coefficient $=-0.557$, $\mathrm{p}=0.011)$ (Table 2B).

In a similar manner, $75.4 \%$ of the variability of the area under the insulin curve before chemotherapy can be attributed $(\mathrm{F}=6.11, \mathrm{p}=0.030)$ to $\mathrm{BMI}$ (coefficient $=1.074, \mathrm{p}=0.007)$, to IL-1 (coefficient $=$ $-1.308, p=0.013$ ) and to Leptin (coefficient $=-1.028$, $\mathrm{p}=0.020)$ (Table 3A). After chemotherapy, $81.8 \%$ (Table 3B) of the variability of the area under the 
A

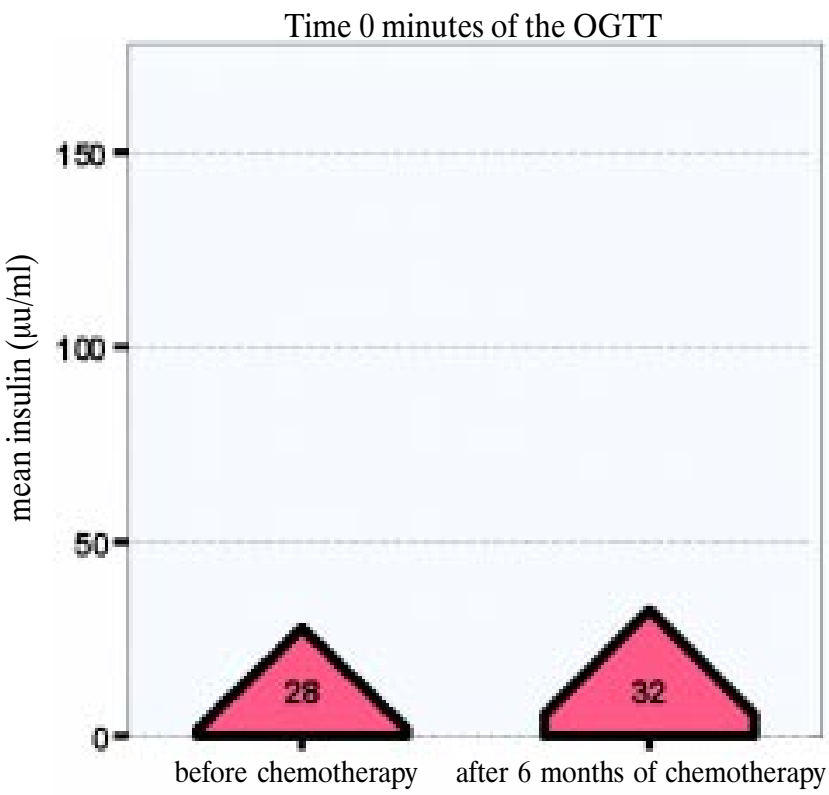

Time of examination

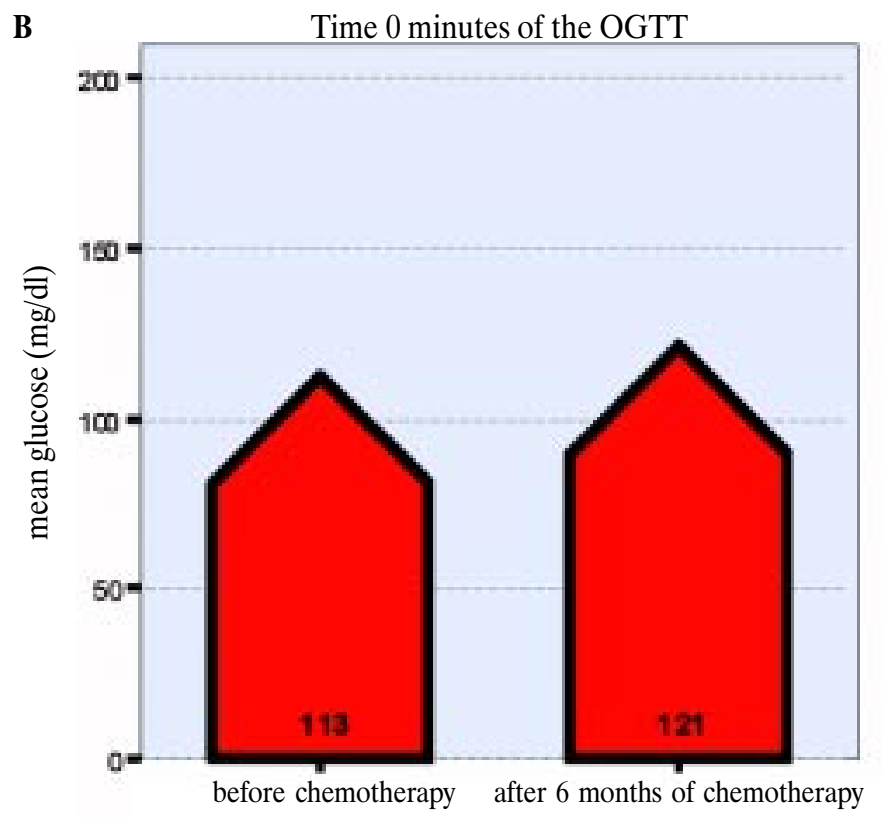

Time of examination

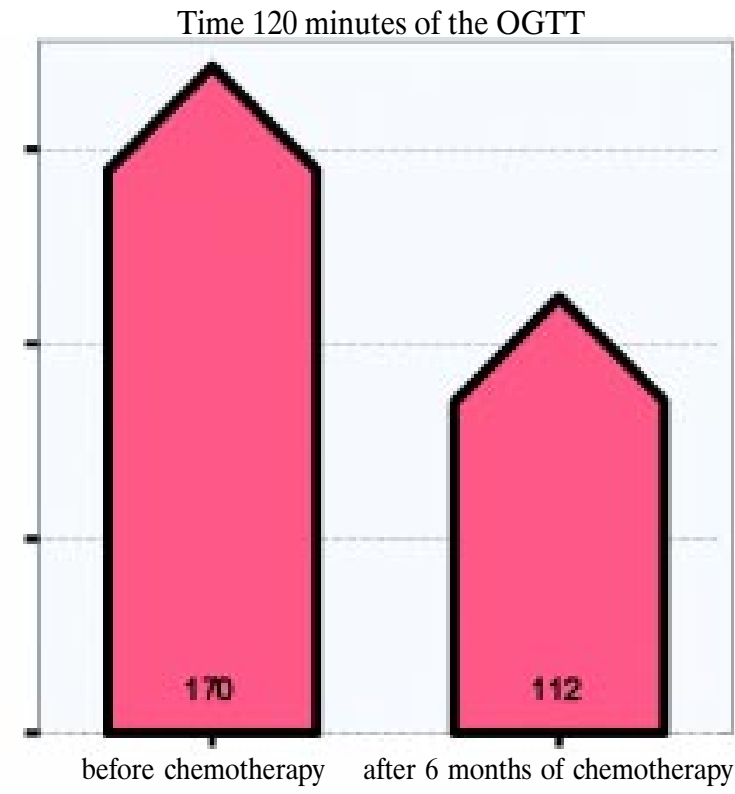

Time of examination

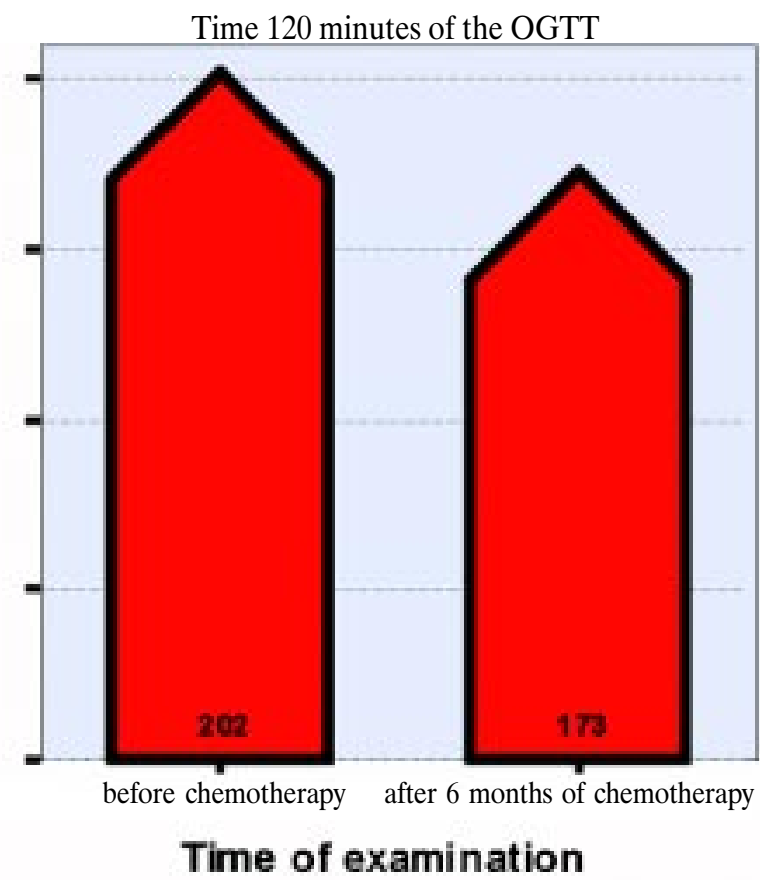

Figure 1. Plasma insulin (A) and glucose (B) levels at time 0 and 120 minutes of the OGTT prior to and following 6 months of chemotherapy. For SI units multiply by 7.175 for insulin and 0.05 for glucose.

insulin curve can be attributed $(\mathrm{F}=9.01, \mathrm{p}=0.012)$ to BMI (coefficient $=0.841, \mathrm{p}=0.005)$, to IL-1 (coefficient $=0.459, \mathrm{p}=0.039$ ) and to IL-8 (coefficient $=0.512, \mathrm{p}=0.039)($ Table $3 \mathrm{~B})$.

No relationship is noticed between insulin levels at time 0 of the OGTT and BMI before and after chemotherapy (Figure 2A).

Before chemotherapy, there is a suggestive positive relationship between BMI and 120 minutes insulin levels, $(\mathrm{p}=0.147$, after controlling for age $)$, 
Table 2. Multiple Regression Analysis with insulin levels at 120 minutes of the OGTT as the dependent variable.

\begin{tabular}{lccc}
\hline \multicolumn{4}{c}{ A. Before chemotherapy* } \\
\hline Model & Coefficient & $\mathbf{t}$ & p-value \\
(constant) & & -3.890 & 0.012 \\
\hline BMI & 1.051 & 5.131 & 0.004 \\
IL-6 & -0.310 & -1.838 & 0.126 \\
TNF- $\alpha$ & -0.325 & -1.888 & 0.118 \\
PDGF & -0.955 & -4.510 & 0.006 \\
\hline \multicolumn{4}{c}{ B. After $\mathbf{6}$ months of chemotherapy** } \\
\hline Model & Coefficient & $\mathbf{t}$ & p-value \\
(constant) & & -3.437 & $\mathbf{0 . 0 1 1}$ \\
\hline BMI & 0.711 & 4.359 & 0.003 \\
IL-6 & -0.557 & -3.420 & 0.011 \\
\hline
\end{tabular}

$*(\mathrm{~F}=7.96, \mathrm{p}=0.021) ;{ }^{* *}(\mathrm{~F}=15.31, \mathrm{p}=0.003)$

while after chemotherapy, a linear correlation is shown $(\mathrm{r}=0.7084, \mathrm{p}=0.033$ after controlling for age), indicating that when tumor growth is controlled, the well-known linear relationship between BMI and insulin emerges (Figure 2B).

Before chemotherapy, a significant correlation is noticed between PDGF levels at baseline and BMI $\left(r_{s}=0.685, p=0.029\right)$. After 6 months of chemotherapy, this positive relationship between PDGF and
Table 3. Multiple Regression Analysis of the area under the curve (AUC) of plasma insulin values as the dependent variable.

\begin{tabular}{lccc}
\hline \multicolumn{3}{c}{ A. Before chemotherapy* } \\
\hline Model & Coefficient & $\mathbf{t}$ & p-value \\
(constant) & & -2.772 & 0.032 \\
\hline BMI & 1.074 & 4.032 & 0.007 \\
IL-1 & -1.308 & -3.472 & 0.013 \\
Leptin & -1.028 & -3.160 & 0.020 \\
\hline
\end{tabular}

\begin{tabular}{lccc}
\hline \multicolumn{4}{c}{ B. After $\mathbf{6}$ months of chemotherapy** } \\
\hline $\begin{array}{lccc}\text { Model } \\
\text { (constant) }\end{array}$ & Coefficient & $\mathbf{t}$ & $\mathbf{p}$-value \\
BMI & & -3.852 & 0.008 \\
IL-1 & 0.841 & 4.327 & 0.005 \\
IL-8 & 0.459 & 2.634 & 0.039 \\
\hline${ }^{*}(\mathrm{~F}=6.11, \mathrm{p}=0.030) ;{ }^{* *}(\mathrm{~F}=9.01, \mathrm{p}=0.012)$
\end{tabular}

BMI is very weak $\left(r_{s}=0.188, p=0.603\right)$ (Figure 3$)$. Moreover, before therapy there is a suggestive negative relationship between basal VEGF (Figure 4) and BMI $\left(\mathrm{r}_{\mathrm{s}}=-0.588, \mathrm{p}=0.074\right)$.

Further exploration of the factors affecting prechemotherapy PDGF levels with multiple regression analysis reveals that BMI loses its predictive significance and $72.1 \%$ of the variability of PDGF levels is attributed $(\mathrm{F}=9.03, \mathrm{p}=0.011)$ to IL-8 (coeffi-
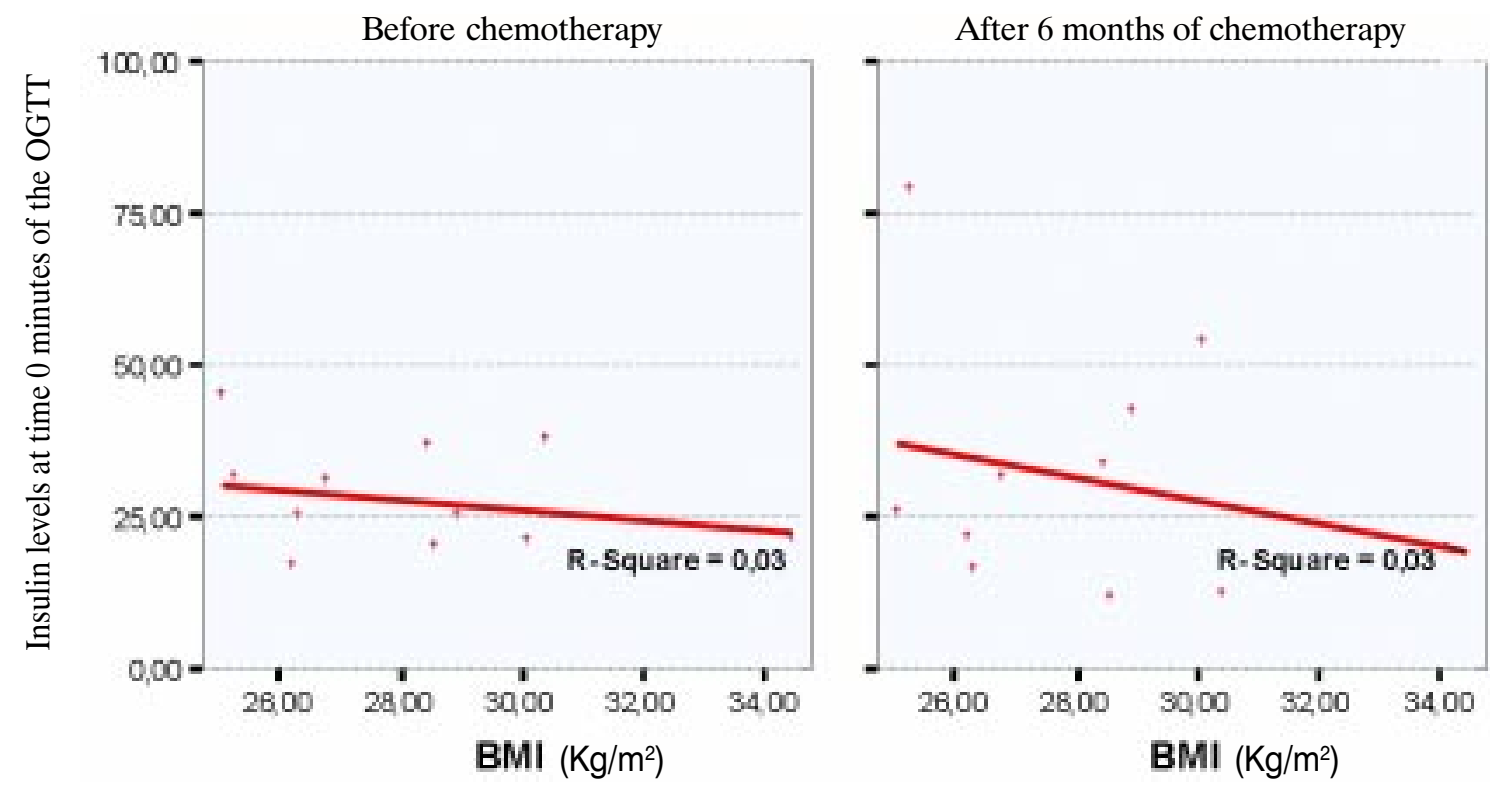

Figure 2A. Relationship between plasma insulin levels at time 0 of the OGTT and BMI prior to and following 6 months of chemotherapy (after controlling for age, $p=0.603$ before chemotherapy and $p=0.613$ after 6 months of chemotherapy). 

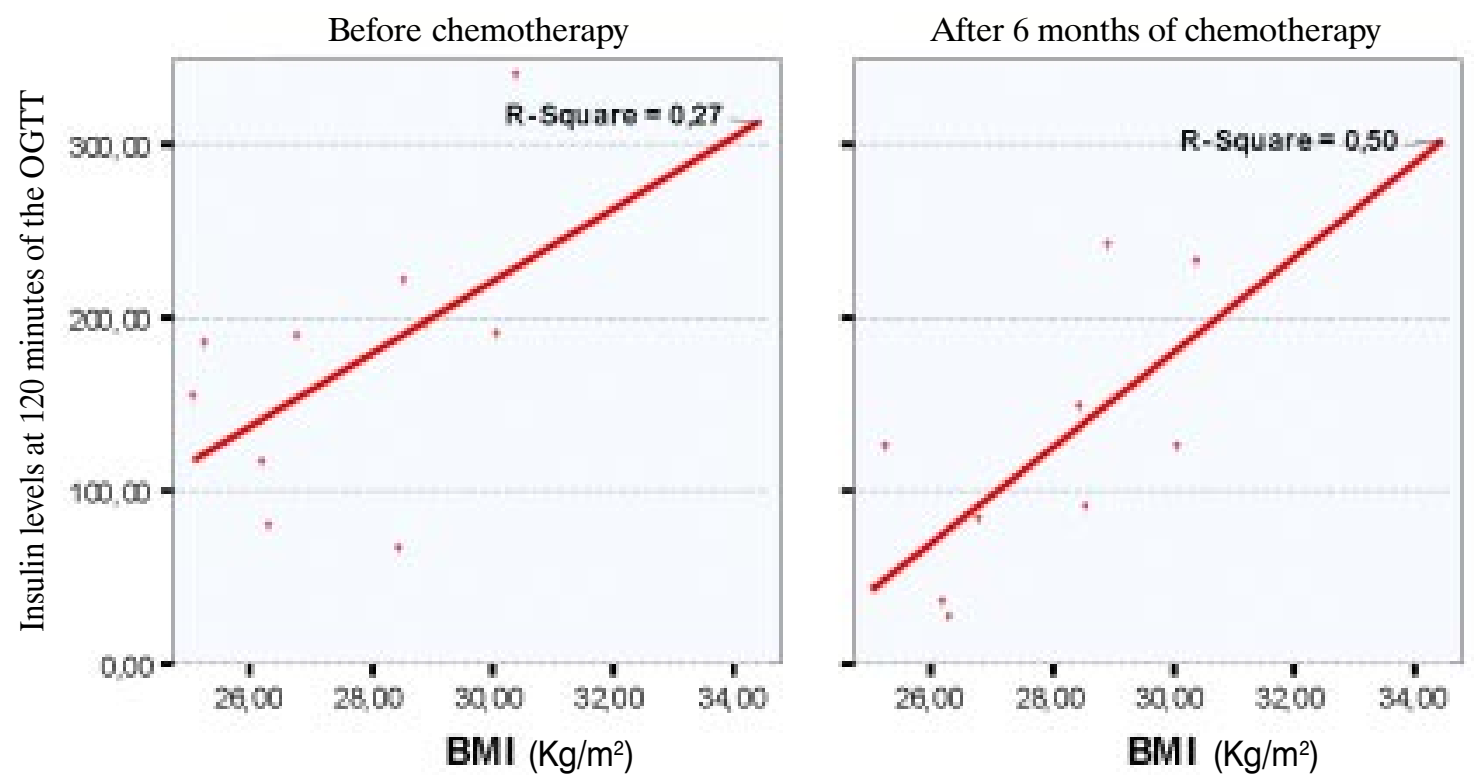

Figure 2B. Relationship between plasma insulin levels at 120 minutes of the OGTT and BMI prior to and following 6 months of chemotherapy (after controlling for age, $p=0.147$ before chemotherapy and $p=0.033$ after chemotherapy).

cient $=-0.621, \mathrm{p}=0.017)$ and to IL-1 (coefficient $=$ $0.546, \mathrm{p}=0.029)($ Table $4 \mathrm{~A})$. In a similar manner, multiple regression analysis after chemotherapy, with PDGF as the dependent variable, reveals that $95.8 \%$ of the variability of PDGF levels is now attributed $(\mathrm{F}=18.21, \mathrm{p}=0.007)$ to IL-1 (coefficient $=$
$-0.615, \mathrm{p}=0.010)$, to IL-6 (coefficient $=-0.682$, $\mathrm{p}=0.015)$ to TNF- $\alpha$ (coefficient $=0.560, \mathrm{p}=0.017$ ) and to VEGF (coefficient $=0.552, \mathrm{p}=0.006)$ (Table 4B). As regards VEGF levels, multiple regression analysis reveals that before chemotherapy there is a negative relationship between VEGF and WC.
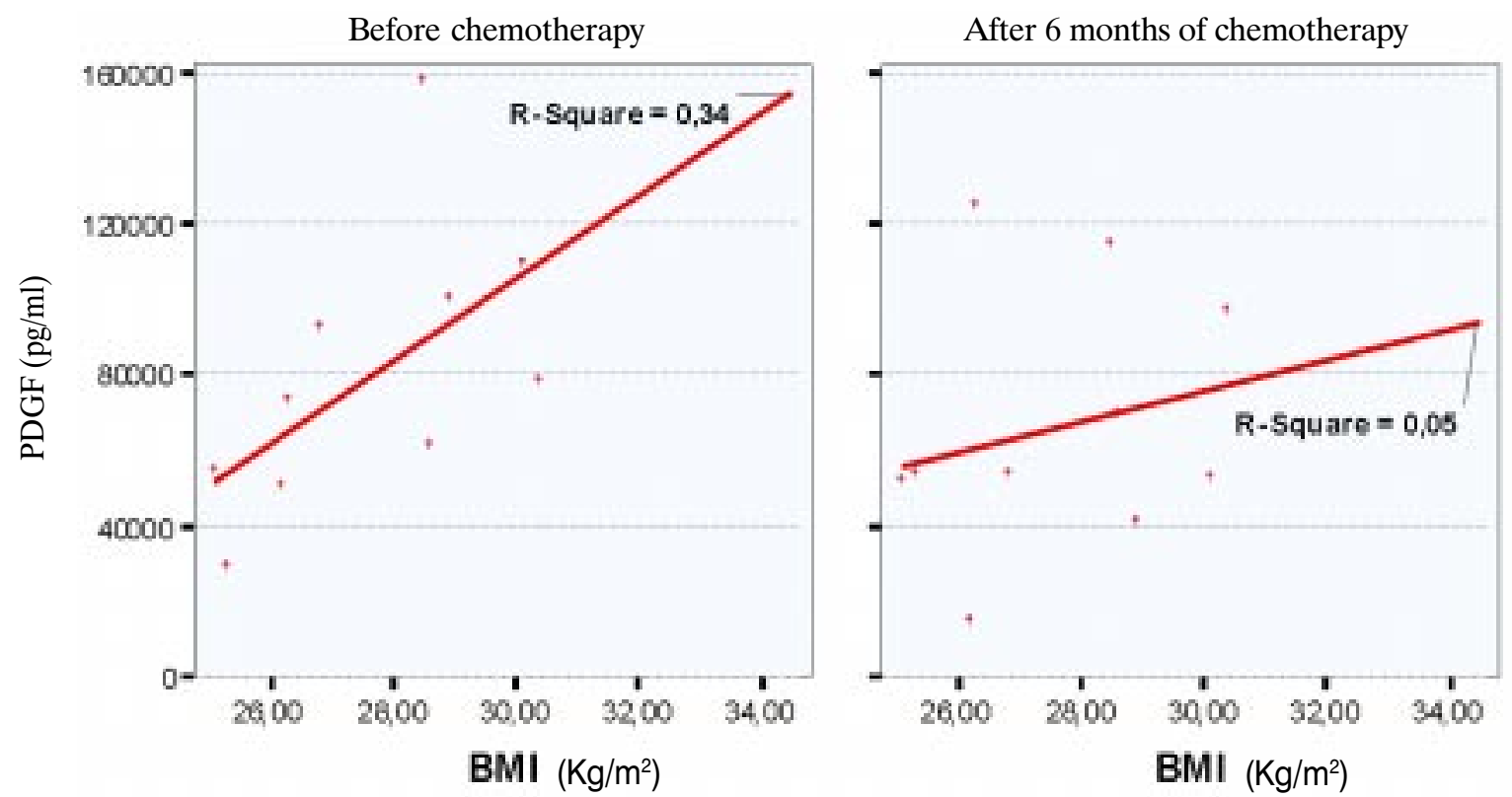

Figure 3. Relationship between PDGF levels and BMI, before and following 6 months of chemotherapy (before chemotherapy $r_{s}=0.685, p=0.029$ and after chemotherapy, $\left.r_{s}=0.188, p=0.603\right)$. 
Specifically, $76.8 \%$ of the variability of VEGF levels before glucose administration is attributed $(\mathrm{F}=11.61, \mathrm{p}=0.006)$ to $\mathrm{WC}$ (coefficient $=-0.542$, $\mathrm{p}=0.023)$ and to TNF- $\alpha$ (coefficient $=0.820$, $\mathrm{p}=0.003)$ (Table 5A). After chemotherapy WC loses its predictive value regarding VEGF levels, while PDGF enters the model as the most significant factor. Specifically, $95.4 \%$ of the variability of VEGF levels is attributed $(\mathrm{F}=10.33, \mathrm{p}=0.041)$ to IL-1 (coefficient $=0.789, \mathrm{p}=0.044)$, to IL-6 (coefficient $=$ $0.910, p=0.040)$, to TNF- $\alpha$ (coefficient $=-0.867, p=$ 0.026 ) and to PDGF (coefficient $=1.545, \mathrm{p}=0.006$ ) while for WC, coefficient $=-0.305, p=0.116$ (Table $5 B)$.

\section{DISCUSSION}

Since insulin, PDGF, VEGF and cytokines are related to breast cancer, it is only natural for some questions to arise: What-if any-is the influence of chemotherapy on these parameters and what is the relationship between modifications of these parameters and certain anthropometric measurements such as BMI to the therapeutic outcome. The real target behind these questions is to find out if breast cancer patients could, besides their conventional therapy, be benefited by any modification of insulin, growth factors and cytokine levels.

Adipose tissue is, through its aromatase action, the source of postmenopausal estrogens. Obesity,

Table 4. Multiple Regression Analysis of PDGF levels

\begin{tabular}{lccc}
\hline \multicolumn{4}{c}{ A. Before chemotherapy* } \\
\hline $\begin{array}{lccc}\text { Model } \\
\text { (constant) }\end{array}$ & Coefficient & $\mathbf{t}$ & p-value \\
& & 3.777 & 0.007 \\
\hline IL-8 & -0.621 & -3.107 & 0.017 \\
IL-1 & 0.546 & 2.729 & 0.029 \\
\hline \multicolumn{4}{c}{ B. After chemotherapy** } \\
\hline Model & Coefficient & $\mathbf{t}$ & p-value \\
(constant) & \multicolumn{4}{c}{0.001} \\
\hline IL-1 & -0.615 & 9.100 & 0.010 \\
IL-6 & -0.682 & -4.631 & 0.015 \\
TNF- $\alpha$ & 0.560 & -4.098 & 0.017 \\
VEGF & 0.552 & 3.933 & 0.006 \\
IGF-1 & -0.284 & 5.208 & 0.057 \\
\hline
\end{tabular}

$*(\mathrm{~F}=9.03, \mathrm{p}=0.011) ;{ }^{* *}(\mathrm{~F}=18.21, \mathrm{p}=0.007)$
Table 5. Multiple Regression Analysis of VEGF levels

\begin{tabular}{lccc}
\hline \multicolumn{4}{c}{ A. Before chemotherapy* } \\
\hline Model & Coefficient & $\mathbf{t}$ & p-value \\
(constant) & & 3.188 & 0.015 \\
\hline WC & -0.542 & -2.908 & 0.023 \\
TNF- $\alpha$ & 0.820 & 4.394 & 0.003 \\
\hline \multicolumn{4}{c}{ B. After chemotherapy* } \\
\hline Model & Coefficient & $\mathbf{t}$ & p-value \\
(constant) & \multicolumn{4}{c}{0.873} \\
\hline IL-1 & 0.789 & 3.367 & 0.044 \\
IL-6 & 0.910 & 3.481 & 0.040 \\
TNF- $\alpha$ & -0.867 & -4.089 & 0.026 \\
IGF-1 & 0.465 & 3.102 & 0.053 \\
PDGF & 1.545 & 7.112 & 0.006 \\
WC & -0.305 & -2.195 & 0.116 \\
\hline$*(F-11.61$ & . & &
\end{tabular}

$*(\mathrm{~F}=11.61, \mathrm{p}=0.006) ; * *(\mathrm{~F}=10.33, \mathrm{p}=0.041)$

and more specifically central obesity, which is usually the case in postmenopausal women and, in our patients, induces peripheral tissue insulin resistance and consequent hyperinsulinism and overeating, which promote further weight gain. ${ }^{23,28}$ Insulin, with or without estrogen interaction, could lead to increased risk for breast cancer development.

Malignancy in general, and in our case mammary tissue malignancy, is a well recognized insulinresistant state, further increasing insulin levels, creating a vicious cycle as regards malignant transformation. Moreover, cytokines, markers of low-grade inflammation, are implicated in insulin-resistant states and hyperinsulinemia, and it is through this path that they constitute an increased risk for type 2 diabetes and for conditions associated with hyperinsulinism such as breast cancer. So far pertinent studies have arrived at conflicting results with regard to cytokine action on mammary malignancy. Thus, IL-6 levels have been correlated with a shorter survival of breast cancer patients, ${ }^{12,14}$ whereas it has been shown that down-regulation of IL-6 is associated with highly malignant mammary carcinomas. ${ }^{17}$

Our study, which was conducted in obese, postmenopausal women, did not disclose any difference in cytokine levels before and after chemotherapy, which was successful in stabilizing the disease. 
Before chemotherapy, there is a suggestive relationship between BMI and 120 insulin levels, although not statistically significant $(p=0.147$, after controlling for age), while after chemotherapy, a linear correlation is shown $(r=0.7084, p=0.033$ after controlling for age), indicating that when tumor growth is controlled, then the well-known linear relationship between BMI and insulin emerges (Figure 2B).

Before chemotherapy, a positive relationship was revealed between PDGF and BMI (Figure 3) and a suggestive negative one between VEGF and BMI (Figure 4). These two results, although conflicting and confusing, could be explained by the assumption that while PDGF, which acts as an oncogenic growth factor, is higher in obese women, VEGF, whose levels come in parallel with the burden of metastases, is higher in malignancy afflicted women with lower BMI, that is to say, the more cachectic women. The relationship between VEGF levels and BMI before chemotherapy accords with the negative relationship between VEGF and WC. It is of interest that the positive relationship between PDGF and BMI, which has not been explored so far in the literature, changes after chemotherapy.

Our study also revealed that after chemothera-
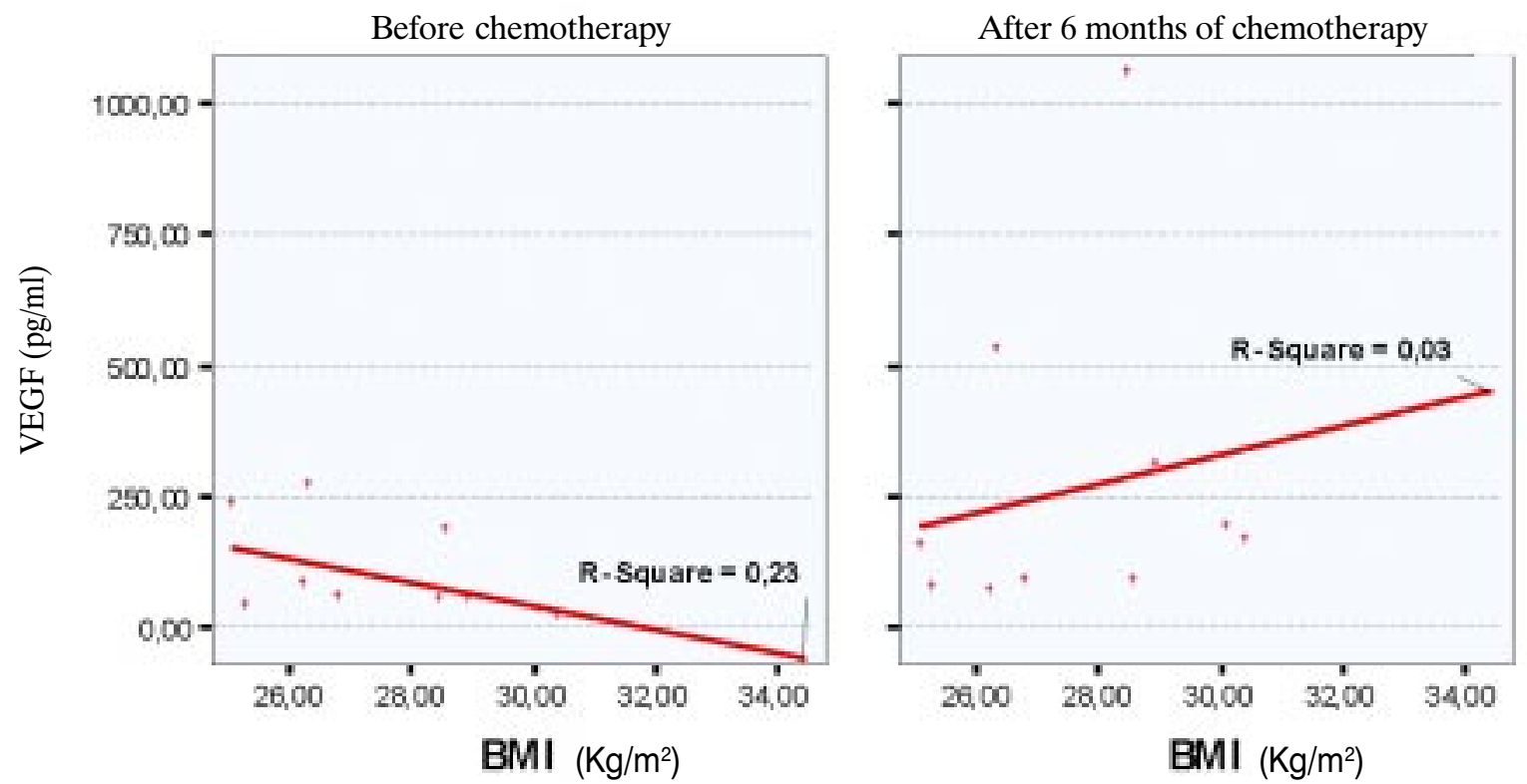

Figure 4. Relationship between VEGF levels and BMI before and after chemotherapy (before chemotherapy $r_{s}=-0.588, p=0.074$ and after chemotherapy $\left.r_{s}=0.406, p=0.244\right)$. 
els and BMI is established and if it proves to be a contributing factor in breast cancer patients, then by keeping BMI at low levels, a more favorable outcome may be expected. More studies will answer this very important question.

\section{REFERENCES}

1. Xavier E, Di-Sunyer, 2002 The Obesity Epidemic: Pathophysiology and Consequences of Obesity. Obes Res: Suppl 2: S97-S103.

2. Calle E, Rodriguez C, Walker-Thurmond K, et al, 2003 Overweight, Obesity and Mortality from Cancer in a prospectively studied Cohort of US Adults. N Engl J Med 348: 1625-1638.

3. Haber D, 2000 Roads Leading to Breast Cancer. N Engl J Med 343: 1566-1568.

4. Patricia Hartge, 2003 Genes, Hormones and Pathways to Breast Cancer. N Engl J Med 348: 2352-2354.

5. Ziegler RG, Hoovert RN, Nomura AMY, et al, 1966 Relative weight, weight change, height and breast cancer risk in Asian-American women. J Natl Cancer Inst 88: 650-660.

6. Pazazzini F, LaVecchia C, Negri E et al, 1990 Anthropometric variables and risk of breast cancer. Int J Cancer 45: 397-402.

7. Sellers TA, Kushi LH, Potter JD, et al, 1992 Effect of family history, body-fat distribution and reproductive factors on the risk of postmenopausal breast cancer. N Engl J Med 326: 1323-1329.

8. La Vecchia C, Negri E, Franceschi S, et al, 1997 Body mass index and postmenopausal breast cancer: an agespecific analysis. Br J Cancer 75: 441-444.

9. Clemons M, Goss P, 2001 Estrogen and the risk of breast cancer. N Engl J Med 344: 276-285.

10. Seymour L, Dayer D, Besmoda WR, 1993 Tissue platelet derived growth factor (PDGF) predicts for shortened survival and treatment failure in advanced breast cancer. Breast Cancer Res Treat 26: 247-252.

11. Kurebayashi J, Otsuki T, Kunisue H, et al, 1999 Expression of vascular endothelial growth factor (VEGF) family members in breast cancer. Jpn J Cancer Res 90: 977-981.

12. Benoy I, Salgado R, Colpaert C, et al, 2002 Serum interleukin 6, plasma VEGF, and VEGF platelet load in breast cancer patients. Clin Breast Cancer 2: 311-315.

13. Wu Y, Saldana L, Chillar R, et al, 2002 Plasma vascular endothelial growth factor is useful in assessing progression of breast cancer post surgery and during adjuvant treatment. Int J Oncol 20: 509-516.
14. Bachelot T, Ray-Coquard I, Menetrier-Caux C, et al, 2003 Prognostic value of serum levels of interleukin 6 and serum and plasma levels of vascular endothelial growth factor in hormone-refractory metastatic breast cancer patients. Br J Cancer 88: 1721-1726.

15. Hong L, Fredriksson L, Xuri L, at al, 2003 PDGF-D is a potent transforming and angiogenic growth factor. Oncogene 22: 1501-1510.

16. Heldin CH, Westermark B, 1999 Function of Platelet Derived Growth Factor Phys Rev 79: 1283-1316.

17. Fontanini G, Campani D, Roncella M, et al, 1999 Expression of interleukin 6 (IL-6) correlates with oestrogen receptor in human breast carcinoma. $\mathrm{Br} \mathrm{J}$ Cancer 80: 579-584

18. Purohit A, Newman S, Reed M, 2002 The role of cytokines in regulating estrogen synthesis: implications for the etiology of breast cancer. Breast Cancer Res 4: 65-69.

19. Lippman ME, Dickson RB, Kasid A, et al, 1986 Autocrine and paracrine growth regulation of human breast cancer. J Steroid Biochem 24: 147-154.

20. Cullen JK, Yee D, Sly WS, et al, 1990 Insulin-like growth factor receptor expression and function in human breast cancer. Cancer Res 50: 48-53.

21. Stoll BA, 2002 Oestrogen/Insulin-like growth factor-1 receptor interaction in early breast cancer: clinical implications. Ann Onc 13: 191-196.

22. Katzenellenbogen B, Katzenellenbogen J, 2000 Estrogen receptor transcription and transactivation: Estrogen receptor alpha and estrogen receptor beta-regulation by selective estrogen receptor modulators and importance in breast cancer. Breast Cancer Res 2: 335344.

23. Cosford R, 1999 Insulin Resistance, Obesity and Diabetes: The Connection. ACNEM 18: 3-10.

24. Nestler et al, 1992 Insulin inhibits adrenal 17,20 lyase activity in man. J Clin Endocr Metab 74: 362-367.

25. Goodwin P, Ennis M, Pritchard Kl, et al, 2002 Fasting Insulin and outcome in early-stage Breast Cancer: Results of a Prospective Cohort Study. J Clin Onc 20: 42-51.

26. Matthews DR, Hosker JP, Rudenski AS, et al, 1985 Homeostasis model assessment: insulin resistance and $\beta$-cell function from fasting plasma glucose and insulin concentrations in man. Diabetologia 28: 412-419.

27. Simpson E, Rubin G, Clyne C, et al, 1999 Local estrogen biosynthesis in males and females. Endocr Relat Cancer 6: 131-137.

28. Stoll BA, 2002 Upper abdominal obesity, insulin resistance and breast cancer risk. Int J Obes 26: 747-753. 